\title{
My view-A new strategy for progress in weed science
}

\author{
Nicholas Jordan \\ Department of Agronomy and Plant Genetics, \\ University of Minnesota, St. Paul, MN 55108
}

What are the most important goals for our weed science profession? In my view, there are two. First, we must contribute to the dramatic increases in global food and fiber production that will be needed soon, by increasing the overall effectiveness of weed management. The second is broader: we must develop weed management methods that promote the well-being of human communities and their ecological support systems. Progress toward both goals will require a change in weed management. From its present reliance on herbicides and tillage, weed management must become more broad and preventive-in short, more diversified. The most important reason for diversification is that significant limits on overall effectiveness appear to exist for herbicide- and tillage-based weed control, due to herbicide resistance and species shifts. Improving the effectiveness of weed management may well be impossible without diversification.

These goals are certainly not new ones. The real question is: how is weed management to become more diversified, effective, and conducive to community well-being? To do so, I think weed science must significantly expand its selfconception. Currently, we work mainly to provide technical expertise about weed biology and management. I believe that we must also learn to function in a quite different mode: as organizers of a broad and systemic effort to improve weed management.

To see what this might mean in practice, consider the central challenge of diversifying weed management. One necessary element-so-called "alternative" weed control practices with which to diversify weed management-appears to be more or less at hand, although much in need of improvement. Promising options include competitive crop varieties, weed seed predators, and more diversified cropping systems. However, these options are little used, because of often-valid concerns about efficacy, reliability, cost, compatibility with other farm operations, and other disincentives. To bring these practices into wide use, they must be refined and adapted, new ones must be invented, and systemic impediments to their use must be overcome, such as time and labor shortages on-farm and barriers to cropping-system diversification.

The weed science profession, by itself, cannot possibly meet these challenges- there are far too few of us. Instead, we must increase the quantity and diversity of knowledge, ideas, and resources that contribute to better weed management. For example, we must tap currently unused sources of knowledge and concern about weed management (e.g., from crop consultants) and bring these persons into productive interactions with weed science. Better weed management must be co-created by a much-expanded range of contributors.

Can we have any realistic hope for such co-creation, when our potential partners are daily confronted with other problems, e.g., in families, schools, and communities? To develop "co-creative" new working relationships, I advocate a strategy with two key tactics. First, we must clearly state the ultimate purpose of weed management. I propose this statement: our purpose is to develop weed management that supports the well-being of communities, encompassing their social, economic, and environmental well-being. If we can show how our profession supports community well-being, we will give persons outside our profession a very important reason to contribute knowledge and resources to improving weed management. Second, we should seek persons outside our profession who have something to contribute to improved weed management, and engage these individuals in dialogue about how weeds affect communities and natural resources in which these individuals have a stake. Often, these will be nonscientists. We should ask these individuals to step forward as active citizens and contribute to improving weed management. Here, the key is active citizenship-i.e., concern for the place where one lives, in all its dimensions, and active contribution to support the well-being of that place. I suggest that such citizenship exists, and that weed science can call upon it.

If weed scientists use the above strategy, I believe that a whole gamut of new working relationships will result. For example, widespread participatory weed-control research and development might emerge, driven by farmer ingenuity and leading to rapid refinement of "alternative" weed control approaches. For another example, weed ecologists currently have a rather distant relationship with the herbicide industry. The two groups might develop closer working relationships, based on mutual interest in community wellbeing and in weed management that will sustain that wellbeing. A final example: weed scientists might collaborate with environmental advocacy groups to promote more diversified cropping systems, improving both weed management and environmental quality. The key to building these coalitions is to recognize our shared stake in community well-being. A few examples of such new working relationships can be seen. We should greatly expand their number.

Building a capacity to recruit new partners and maintain productive working relationships will certainly be a "growth experience" for our profession! The work ahead is very different from providing technical expertise on weed biology and management. It will challenge us in new ways, and will require new kinds of scholarship and new standards of accountability. It offers exciting and rewarding new opportunities for extensionists, researchers, and private-sector weed scientists. By following this path, we can show how an agricultural science can expand from a narrow conception of its function-providing technical expertise-to a broader conception, in which it serves by organizing a diversified and systemic approach to problem solving in agriculture.

Approved February 7, 1997. 